\section{Anea: Cardialogia}

\section{MÉDICO GESTOR DE CONFLITOS À BEIRA DO LEITO}

\begin{abstract}
MAX GRINBerg ${ }^{1}$
Diretor da Unidade Clínica de Valvopatias do Instituto do Coração do Hospital das Clínicas da Faculdade de Medicina da Universidade de São Paulo - HCF-
\end{abstract} MUSP

É melhor prevenir do que remediar. Prevenir adversidades da conduta é excelente remédio. A quebra de segurança da coagulação para prevenir tromboembolismo traz conformidade a ambas assertivas.

A prudência é a fidelidade ao futuro, ensinam os filósofos. A prevenção da doença cardíaca e os cuidados com a segurança dos métodos aplicados é a parcela do elixir da longa vida que a medicina pode realizar do sonho dos alquimistas.

Cada época tem seus métodos diagnósticos e seus recursos de tratamento. Por séculos, o brasileiro não teve nada além dos órgãos dos sentidos de poucos médicos e além da natureza generosa. O primum non nocere dominava. Sem benefício, que não se fizesse malefício.

Nas últimas décadas, o Brasil passou a acumular beneficência de modo cada vez mais célere. O primum non nocere cedeu lugar à não-maleficência, benefício com o mínimo possível de malefício. Ampliamos e aprofundamos o conhecimento sobre o anátomofuncional do coração e sistemas afins e aplicamos expertise galopante de diagnóstico, terapêutica e de prevenção a muito mais brasileiros. Expandiu-se a necessidade de complementos por variadas áreas do conhecimento florescentes em nossa pátria. As adversidades pela conduta beneficente multiplicaram-se, era de se esperar pelas imperfeições da medicina. A regra é clara, inovam-se os métodos, eles geram expectativas de fazer o bem clínico melhor para o paciente, mas criam-se tensões porque se renova a iatrogenia ${ }^{(1,2,3)}$.

As disciplinas de medicina, as especialidades da medicina e o pressuposto social da medicina projetaram prestígio ao médico. É frequente que haja um membro da família sob cuidados de um médico. As visões prospectivas pessoais e retrospectivas da sociedade harmonizam-se. A qualidade de vida do brasileiro doente tem sido beneficiada. Os indicadores coletivos sinalizam eficiência do estado da arte em medicina, no Brasil. Contudo, drogas de habitual continuidade no uso são causas comuns de efeitos adversos. Considerar que "faz parte" é atitude reducionista. O que é método de comprovada beneficência conceitual para o coletivo requer uma apreciação do benefício de fato para cada indivíduo usuário. 0 feedback é entre médico e paciente e não entre medicina e paciente.

O cenário é de progresso e cada médico brasileiro desempenha o papel de responsável pelo doente e pela imagem da medicina. Ele está conectado à universalização da especialidade e direcionado para as peculiaridades regionais. A missão de especialista com sensibilidade generalista Ihe exige acautelarse tecnocientificamente, assegurar-se que está apto a promover o bem clínico com o máximo de segurança para o paciente. 0 médico bem formado intui do cotidiano que não basta seguir os protocolos, é essencial que promova ajustamentos à expressão nosológica do "seu" paciente. Desta forma, haverá a contrapartida do paciente manifestar-se por "meu" médico, os possessivos atestam o bom vínculo. Como também, a "nossa" Diretriz é bemvinda embaixatriz da medicina na beira do leito, desde que não seja, tão somente, um verniz de conhecimento do médico ${ }^{4,5,6}$.

O sem parar de novidades torna o título de especialista pela sociedade de especialidade um compromisso com uma sucessão de pedágios informais da habilitação profissional. Eles vão surgindo a cada expansão da fronteira do estado da arte. Não há como prever o número de pedágios a serem transpostos até a aposentadoria. Eles são, certamente, muitos, têm sido nos últimos anos. Eles acontecem sempre que a trajetória do profissionalismo do médico sofre o impacto da nova tecnologia, da nova visão da doença e do novo expressar-se do doente. Em consequência, o especialista tem que ser um renovado clínico, cirurgião, ultrassonografista, etc..., continuadamente atual. Avanços e recuos, porque assim caminha o conhecimento científico, mas nunca estático no diploma de médico. Sempre a mais do mesmo.

A beira do leito é o poder moderador dos processos de renovação da especialidade ${ }^{(7)}$. Ela possui o clássico como sólido ponto de referência. Ela dá o tom dos fundamentos que resistem ao tempo. Ela representa o controle de qualidade a que os aspirantes ao clássico não podem deixar de se submeter. Lá nunca envelhecem o trio simbólico formado por estetoscópio, esfigmomanômetro e raciocínio clínico. Eles formam o núcleo que se expande em busca da completude da beira do leito e que rejeita qualquer viés de evitação pelo novo. Válido para a medicina e para o médico.

0 médico é inquieto e curioso por ofício. Atento às lacunas do saber e às adversidades da assistência, ele recarrega a pesquisa em medicina com hipóteses formuladas pelas necessidades. Quando elas são transformadas em conclusões de utilidade e eficácia e retornam à assistência ${ }^{8}$, o médico apressa-se pelo endosso do real benefício para o paciente. Ele sabe que o tempo é o filtro da beira do leito que faz melhor reconhecer se as adversidades porventura aduzidas são justificáveis ${ }^{9}$. A procura da verdade implica em duvidar sempre.

Vitoriosas sobre o tempo, as tradições da beira do leito são respeitáveis. Desrespeitá-las é contra-senso. O mais emblemático dos valores da beira do leito chama-se relação médicopaciente. Hipocrática, ela acompanhou cada geração de médico -já são cerca de 100 gerações desde o pai da medicina. Ela se afigura eterna, disso ninguém duvida. É impossível que possa perder a primazia da beira do leito, enquanto médico e paciente forem seres humanos. E como eles são, a não-maleficência é 
desafio da beira do leito que muitas vezes supera o da beneficência, nas especialidades médicas onde a alta preocupação com o prognóstico requer estratégias agressivas.

A gravidade das enfermidades exige firmeza do sustentáculo na relação médico-paciente. 0 vigor da relação não é um simples estar presente fazendo prescrições "clinicamente corretas" na beira do leito. Ele é energizado quando se conhece a pessoa bastante para poder ser seu médico, quando se empreende o raciocínio clínico em consonância com a disponibilidade da tecnologia e quando se reduz ao mínimo possível as adversidades das condutas necessárias.

A soberania da relação médico-paciente é sensível a diuturnos movimentos e contra movimentos do contexto social, moral, cultural e econômico da medicina. Um quilômetro de distância entre cenários do vínculo é suficiente para modificar a expressão de receptores e agentes. A prática das especialidades médicas subentende heterogeneidades, mesmos profissionais podem, inclusive, ter atividades e comportamentos distintos em diferentes ambientes. Um denominador comum, que a sociedade deseja, é a mesma atenção com a segurança para o paciente.

Nenhum fator de segurança respeitante da ética deve ser "jogado para debaixo do tapete" da beira do leito, pois amanhã poderemos tropeçar no calombo. Há que se evitar, tanto o preconceito que se acumula como resto de novas idéias, quanto a repetição dos atrasos, acelerações e descompassos por puro personalismo magister dixit. Cada nova proposição bem fundamentada no conhecimento da medicina, na capacitação do médico/equipe em aplicar e na atitude do médico na condução deve ser respeitada pelas evidências, criticada pelas vivências e decidida na anuência se aplicável ou não aplicável, sempre com a etiqueta de fronteira provisória.

As especialidades médicas colecionam inumeráveis situações onde uma visão de imprudência de ontem tornou-se visão de negligência atual. Ao mesmo tempo, que "obrigações" de outrora converteram-se em peças de museu. É só ler alguns trechos de capítulos da primeira edição de um livro de texto, como o Braunwald (1980), bíblia da cardiologia. Cada momento tem uma veracidade de zelo e de prudência, onde a mutabilidade deve ser esperada a reboque de novos conceitos e disponibilidades.

Por isso, o justo conceito da temporalidade da recomendação sustentada pela literatura médica e por seus literatos. Convivemos com um "Plantão controlador" da admissão ou da demissão da conveniência de condutas. Ele contribui para o exercício do profissionalismo a que o médico se compromete, à luz da fidelidade ao momento, da simplicidade em acolher sem dogmatizar e da coragem em prol da grandeza da relação médico-paciente. Há que ter atenção, contudo, a conflitos de interesse, que existem sob diversas modalidades. Mas o ideal do médico juramentado é que ele tenha o máximo de interesse nos conflitos do cotidiano.

Pois não há beira do leito sem conflitos, especialmente porque nela casos são minoria, predominam os acasos (ditados pela personalidade do paciente e suas comorbidades). A doença que está descrita no próximo capítulo de livro com conflitos pedagogicamente minimizados não apresenta mesmas expressões nos próximos doentes. Anamnese, exame físico, exames complementares, raciocínio clínico, tomada de decisão diagnóstica e terapêutica, acompanhamento da evolução, resolução de adversidades, alta hospitalar e até constatação de causa-mortis são individualizados. Um pretenso mentalizado padrão clínico pode ser desconstruído após não mais do que três pacientes atendidos. É o conjunto da pessoa que dá expressão aos conflitos. E são os conflitos que dão sentido ao ser médico.

A solidariedade do médico às necessidades do paciente gera a interdependência que faz aflorar os conflitos. Por isso, a beira do leito reúne convergências e divergências convivendo numa mesma relação médico-paciente, proporções variadas de bons e maus aspectos, qualificados com propriedade, apenas se apreciados pela óptica de quem os vivencia.

O médico está sempre selecionando critérios para atuar com zelo e prudência em meio a alertas sobre quebra de segurança para o paciente. É comum, mesmo para quem está com desconforto, entender a beneficência de um medicamento e não aceitar o benefício, porque ele privilegia a não-maleficência e deseja evitar o efeito adverso. Ele se vê praticando a fidelidade ao seu futuro, no seu entendimento, num nível de realidade diferente da argumentação do médico sobre a beneficência. Há o inverso, o paciente comunga com o conceito da beneficência de parar de fumar, mas privilegia o prazer de momento e age como se imutável fosse a sensação atual de pessoa saudável.

No processo de deliberação sobre beneficência e não-maleficência, a autenticidade é essencial para dar o valor do respeito à relação médico-paciente. 0 médico empenha-se com métodos que tenham chance de sucesso, mas ele não promete resultados e sinaliza sobre adversidades. Isto se dá porque o seu conhecimento tem como limite superior o que a medicina conhece. E o seu olho clínico não inclui a visão de profeta.

Por outro lado, é autêntico o desejo do paciente pelo resultado, nem sempre ele está interessado no método ${ }^{10}$. Quem está com sede não está preocupado se a fórmula da água contém dois explosivos. O paciente cumpre a receita-método com o mesmo objetivo terapêutico com que ela foi prescrita, mas conjugado com pontos de interesse peculiares, nem sempre prioritários para o médico. Por isso, a beira do leito é estimulante e conflituosa. Ajusta-se o foco para a tecnologia, desfoca-se o caráter humano do atendimento. Privilegia-se o desejo do paciente e surge a sensação de estar numa prática de negligência ("aprendemos que era para fazer") para não cometer uma violência à pessoa. O médico aprende a gerir os muitos conflitos numa educação continuada em serviço.

A beira do leito faz-se viva pelos conflitos. Em ausência, para que beira do leito? Esta conceituação sustenta a pedagogia do "pode-se fazer melhor" e do "não paramos de procurar evidências". O checklist é dinâmico. Ele dá a métrica do comprometimento com a relação médico-paciente, na qual de nenhum modo, este último deve se comportar como um ser passivo, pois não é um objeto. Ele precisa demonstrar, se houver, a diversidade de opinião. Qualquer conflito precisa estar explícito. É fator de segurança para o paciente.

O profissionalismo do médico brasileiro na beira do leito requer reconhecer o seu grau de envolvimento na gestão de conflitos da relação médico-paciente. Ele tem que se preparar para entender uma variedade de "etiopatogenias" ligadas a terceiros da relação médico-paciente. 
Relacionamos 10 conflitos do cotidiano de interesse do "médico-gestor":

1- Conflito de diagnóstico, que chamamos de diagnóstico diferencial. A interdisciplinaridade é de utilidade resolutiva;

2- Conflito de terapêutica, que chamamos de conduta. O equilíbrio entre a experiência pessoal e a experiência coletivizada da literatura é essencial;

3- Conflito de antecipação, que chamamos de medida de prevenção. Dados epidemiológicos, conclusões de pesquisas e opiniões no âmbito da relação médico-paciente são exigidos;

4- Conflito entre a beneficência e a não-maleficência. A manifestação do paciente é fundamental;

5- Conflito com desejos e pontos de vista do paciente. 0 exercício da tolerância é bem-vindo;

6- Conflito com familiar do paciente. A inclusão para os esclarecimentos é indispensável, mesmo estando o paciente capaz;

7- Conflito com atitude de outro médico. O respeito ao Código de Ética Médica deve balizar a resolução das divergências.

8- Conflito com outro profissional da saúde. O interesse pela incorporação deve predominar.

9- Conflito com profissional não da área médica. Conhecimentos mínimos sobre responsabilidade civil e penal são desejáveis;

10- Conflito de administração, que chamamos de infraestrutura. O planejamento estratégico é obrigatório.

0 médico brasileiro está habituado à pluralidade de realidades da beira do leito. Isto significa que está preparado para aplicar a ciência. Não somente a partir da leitura crítica de artigos científicos, segundo preceitos acadêmicos, como um filtro a mais do que já aconteceu adrede à publicação. Mas, principalmente, porque ele apreende da experiência coletivizada da literatura mentalizando as especificidades dos conflitos que acontecem habitualmente na beira do leito onde exerce a sua parte na relação médico-paciente. Ele discorre pelo texto construindo os ajustes pela experiência pessoal. Prevenir-se é o bom remédio!

\section{Correspondência:}

Rua Manoel Antonio Pinto, 4 ap.21 - A

São Paulo - SP

CEP: 05663-020

\section{Referências}

1. Moore T, Cohen M, Furberg C. Serious adverse drug events reported to the food and drug administration, 1998-2005. Arch Intern Med. 2007;167:1752-9.

2. Pereira, AC, Franken RA, Sprovieri SRS, Golin V. Iatrogenia em cardiologia. Arq Bras Cardiol. 2000; 75:75-8.

3. Schmader KE, Hanlon JT, Pieper CF, Sloane R, Ruby CM, Twersky J, et al. Effects of geriatric evaluation and management on adverse drug reactions and suboptimal prescribing in the frail elderly. Am J Med. 2004:116:394-401.

4. Tan KBH. Clinical practice guidelines:a critical review. Int J Health Care Qual Assur Inc Leadersh Health Serv. 2006; 19:195-220

5. Grinberg M. Acaso da beira do leito, causo da bioética. Arq Bras Cardiol. 2006;87, e257-e61.

6. Grinberg M. E(ti)cossistema da cardiologia, diretriz - mecenas do estado da arte. Arq Bras Cardiol. 2007;89:e-136-e-62.

7. Papper M. The "practice" of medicine. Ann Intern Med. 2006; 145: 308-9.

8. Titus SL, Wells JA, Rhoades LJ. Repairing research integrity. Nature. 2008;453:980-2

9. Leape LL, Berwick DM. Five years after "To Err is Human": What have we learned? JAMA. 2005;293:2384-90.

10. Broström L, Johansson M, Nielsen MK - "What the patient would have decided": a fundamental problem with the substituted judgment standard. Med Health Care Philos. 2007:10:265-78. 